\title{
A sociologia das desigualdades em educação posta à prova pela segunda explosão escolar: deslocamento dos questionamentos e reinício da crítica*
}

\author{
Jean-Louis Derouet \\ Institut National de Recherche Pédagogique, Groupes d'Études Sociologiques
}

Tradução: Anne Marie Milon Oliveira

Universidade Federal Fluminense, Faculdade de Educação

Na França e nos países influenciados pelos princípios da Revolução Francesa, a questão das desigualdades remete a duas cronologias. Uma delas, a longa, enraíza-se nos planos de educação que floresceram na segunda metade do século XVIII (Backso, 1982; Van Haecht, 1985), ligando a igualdade educativa à realização da unidade nacional e ao exercício da cidadania. Essa concepção afirma um certo número de princípios fundadores da modernidade. Primeiramente, a idéia de que a educação é uma tarefa do Estado, e não da Igreja ou das comunidades. Em segundo lugar, formula um projeto de distribuição das posições sociais que valoriza o mérito, em detrimento do nascimento. No entanto, durante muito tempo esta afirmação ficou restrita ao âmbito dos princípios. Isto explica porque o tema das desigualdades ficou ausente

* Artigo publicado originalmente em Éducation et Societés Revue Internationale de Sociologie de l'Éducation (Paris, Bruxelles: Département De Boeck Univeristé, nº 5, 2000/1, dossier "Les inégalités d'éducation: un classique revisité"). Tradução e publicação autorizada em setembro de 2002. do primeiro período da sociologia da educação, iniciada por Durkheim no final do século XIX. Seu problema era a criação de uma consciência coletiva. A questão da mobilidade social não era posta. Em compensação, ela encontra-se no centro da cronologia curta, que corresponde ao projeto de escola única. Até a Segunda Guerra Mundial, o sistema francês estava organizado em duas ordens diferentes. A ordem primária, que escolarizava as crianças das classes populares, conduzia os melhores alunos a um primário superior que culminava no nível do brevet. ${ }^{1}$ As crianças da burguesia, em contrapartida, entravam para o nível secundário ainda nas primeiras classes dos liceus ${ }^{2}$

\footnotetext{
${ }^{1}$ Brevet des collèges: exame que sanciona o fim da primeira
} parte dos estudos secundários, o collège. Este corresponde ao segundo segmento do ensino fundamental brasileiro ( $5^{\mathrm{a}}$ à $8^{\mathrm{a}}$ série $)$ (N.T.).

${ }^{2}$ Estabelecimentos atualmente reservados ao segundo segmento dos estudos secundários (aquele que segue o collège). Até a época citada pelo autor, acolhiam, também, crianças em nível primário, geralmente oriundas da burguesia (N.T.). 
e prosseguiam, salvo acidente, em um curso que as levava ao baccalauréat ${ }^{3}$ e aos estudos superiores. A realização do ideal de igualdade implicava a substituição dessa organização, formada por dois sistemas paralelos, por um sistema organizado em níveis, que teria por base a escola única (Prost, 1981). Tal era o preço a pagar para conferir justiça à seleção daqueles alunos suscetíveis a prosseguirem os estudos superiores. Esse objetivo foi inscrito, desde 1919, no programa do Partido Radical por Ferdinand Buisson e foi confirmado após a Primeira Guerra Mundial pelos Companheiros da Universidade Nova. Inspirou, na época do Front Populaire, ${ }^{4}$ o projeto de Jean Zay, e depois, na época da Libertação, o Plano LangevinWallon. Após a Segunda Guerra Mundial, os pesquisadores começaram a construir o dispositivo empírico que ia suceder à implementação desse plano. $\mathrm{O}$ trabalho de codificação da sociedade, que resultou na criação do Instituto Nacional de Estatística e de Estudos Econômicos (INSEE), chegava a seu termo (Desrosières, 1993) e os sociólogos podiam relacionar a posição social dos pais com a carreira escolar dos filhos. Assim, a questão tornou-se central, no fim dos anos de 1950, com os trabalhos do Instituto Nacional de Estudos Demográficos (INED) (Girard, Bastide \& Porcher, 1963; Girard \& Bastide, 1963), e depois com as interpretações propostas por Bourdieu e Passeron (1964, 1970) e Boudon (1973). Esta questão ocupou a totalidade do campo educacional nos anos de 1960 e 1970, e continua a ocupar hoje um amplo espaço. No entanto, é possível - mesmo que isto seja politicamente incorreto - interrogar-se: se o interesse pelas desigualdades em educação nasceu em uma dada conjuntura, não seria ele chamado a decrescer, ou até mesmo a desaparecer em outra? O debate público está marcado, desde meados dos anos de 1980, por um retorno da questão dos saberes e dos valores, numa

${ }^{3}$ Baccalauréat: exame que corresponde ao certificado de conclusão de curso secundário (N.T.).

${ }^{4}$ Coligação reunindo todos os partidos de esquerda que assumiu o poder em 1936 e promoveu profundas reformas sociais (N.T.). perspectiva que não está longe, mutatis mutandis, de evocar a problemática durkheimiana. De mais a mais, a reivindicação perdeu a parte mais ativa de sua base social. Desde os anos de 1930, a demanda por maior abertura do ensino secundário era uma bandeira das classes médias, que viam nela uma possibilidade de promoção para seus filhos. Esta reivindicação foi atendida nos anos de 1960 e 1970, mesmo que seu atendimento não tenha ocorrido sem decepções (Dubet, 1992). Hoje, o prolongamento incontrolado do movimento de abertura do ensino secundário, desencadeado por essas classes, corre o risco de frustrá-las. Desde 1975, muitos pais temem que a massificação acarrete uma desqualificação deste nível de ensino e que a supressão dos procedimentos de distinção afogue seus filhos num fluxo que não leve a lugar nenhum. Sua reivindicação muda, então, de sentido. Não se trata mais de pedir um maior acesso ao ensino secundário, e depois à universidade, e sim de uma maior transparência, de forma que as famílias, bem-informadas, possam fazer as boas escolhas. A França passa, assim, de uma concepção da democratização, por ela forjada durante os anos de 1930, à da democracy anglo-saxã, na qual os cidadãos são associados às decisões que lhes dizem respeito.

Diante dessa evolução das classes médias, não se pode afirmar que as classes populares tenham retomado essa bandeira e formulado algum ideal capaz de corresponder ao fenômeno hoje chamado de "segunda explosão escolar", isto é, à chegada em massa de alunos aos liceus, que se verifica a partir de meados dos anos de 1980, seguida da chegada em massa de estudantes ao ciclo básico das universidades, no decorrer dos anos de 1990. Na verdade, essas classes não precisam valer-se dos ideais da classe média, já que ninguém pode publicamente questionar esse movimento. O risco, mais velado, é de que o aumento da oferta perca seu sentido, deixando a engrenagem funcionando no vácuo. Um sinal disso é o arrefecimento que se verifica, já há alguns anos, da procura por liceus e, mais recentemente, pelas universidades.

Talvez, para compreender esse fenômeno, seja útil voltar às suas origens. No final dos anos de 1970, 
várias vozes autorizadas previam uma estabilização no crescimento dos efetivos do ensino secundário. $\mathrm{O}$ fluxo demográfico da primeira explosão escolar já havia passado e a integração das crianças das classes médias ao ensino secundário já estava completa. Quanto às classes populares, elas pareciam afastadas demais desse universo para pretender ter acesso a ele imediatamente. Em razão disso, os demógrafos previam um decréscimo dos efetivos nos liceus e recomendavam uma redução nas contratações de docentes (Norvez, 1977). Esta opinião era combatida por outros experts, notadamente por Antoine Prost, cujas pesquisas históricas permitiam situar o fenômeno numa perspectiva mais ampla. A evolução da educação no século XX não pode ser separada daquela que afeta as concepções sobre a família e a juventude. Para além do projeto de democratização e das esperanças de sucesso social, é o lugar mesmo dos jovens na sociedade que mudou (Prost, 1981, 1993). Até os anos de 1960, os jovens de dezesseis a dezoito anos tinham um lugar no mundo do trabalho e aqueles que prosseguiam nos estudos constituíam uma exceção. Nos anos de 1980, já não há mais lugar para um jovem, a não ser na escola. Aqueles que não a freqüentavam aparecem, invariavelmente, quase como marginais. Por isso, no relatório que redigiu em 1963 para o diretor dos Liceus, Antoine Prost prevê a continuidade e até a aceleração da progressão do acesso dos jovens aos liceus. No entanto, o fato de que não há lugar para os jovens fora da escola não basta para dar um sentido à sua presença nela. Este sentido não pode mais se fundar majoritariamente nas esperanças de mobilidade social. Os sistemas de classificação então utilizados mostram que a proporção de executivos em relação ao total da população ativa é de 30\%: $10 \%$ de executivos com nível superior e $20 \%$ com nível médio. Ora, a proporção de cada geração que chegava, na época, ao baccalauréat, era inferior a 30\%, razão pela qual esse diploma constituía uma promessa estatística de se chegar a uma posição invejável. Mas, a partir do momento em que esta proporção se situa entre $60 \%$ e $70 \%$ da população, fica impossível organizar o sistema escolar e os investimentos dos alunos com base nesta promessa. A palavra de ordem ministerial: " $80 \%$ de cada geração com o nível do baccalauréat" justifica esse movimento pela evolução do trabalho e pelo fato de que as tarefas de execução requerem, hoje em dia, capacidades de antecipação e de comunicação que só se desenvolvem com a aquisição de uma cultura geral. Esse argumento revela uma verdade incontestável, mas ele é pouco mobilizador, pois pede aos jovens que consintam em fazer maiores sacrifícios para conseguir posições que as gerações anteriores haviam conseguido com menores esforços. Pode-se até evocar um projeto de realização de si pelo saber, ou um princípio de busca pela perfectibilidade do ser humano, independentes de toda esperança de lucro. A proposta é nobre, mas talvez um pouco nobre demais para ser socialmente realista. Disso surge uma crise que pode ser percebida nos comportamentos cotidianos: o sentido que os alunos constroem para sua presença nos liceus não se refere mais aos desafios propostos pela instituição, e sim a um sistema paralelo que Patrick Rayou chama de Cidade invisível (1998).

Essa dificuldade se encontra também, guardadas as devidas proporções, na área científica. O questionamento sobre as desigualdades perdura e continua muito produtivo, mas ele anda numa velocidade já consolidada, isto é, considera a situação atual baseado na problemática da partilha dos benefícios (Darras, 1966). Com certeza, essas análises permanecem em grande parte pertinentes, mas pensar o estado atual do sistema educativo com instrumentos forjados para dar conta do seu funcionamento durante os "trinta gloriosos" $" 5$ não deixa de acarretar problemas.

Eu proporia, então, três deslocamentos. O primeiro é aquele ligado à crise de confiança no Estado de Bem-Estar Social e à necessidade de levar-se em consideração a ação local. A seguir, vêm as tentativas que chamam a atenção para a pluralidade dos princípios de justiça e propõem substituir o ideal de justiça pelo

\footnotetext{
${ }^{5} \mathrm{Na}$ França, chama-se "Os trinta gloriosos (anos)" o perío-
} do compreendido entre o final da Segunda Guerra Mundial e o primeiro choque do petróleo (N.T.). 
de igualdade. Para concluir, apresentarei os empreendimentos que tentam recompor, ao mesmo tempo, o debate social e o campo científico, aprofundando aspectos até agora negligenciados: a experiência escolar dos alunos e sua relação com o saber. Em todas essas análises, refiro-me prioritariamente ao caso francês, embora saiba que ele não constitui um paradigma universal. Peço que me desculpem por isso, mas trata-se do caso que melhor conheço!

\section{A descentralização e o círculo vicioso da crítica tradicional}

A política dos anos de 1960 tinha por base uma grande confiança no Estado. Não se duvidava de que, quando este realmente queria algo, ele o podia. Esse é, por sinal, o ponto nodal da crítica de Bourdieu e Passeron: se a igualdade educativa alardeada pelas decisões oficiais não progride é porque os discursos são mistificadores e tanto a sociedade como o Estado não querem realmente a democratização. A noção de efeito perverso foi formulada, desde o início dos anos de 1970, por Raymond Boudon (1973, 1977) e foi magnificamente ilustrada pelas pesquisas de Antoine Prost. Ele demonstrou que a "democratização rastejante", que existiu nos anos de 1950, havia parado no momento em que o Estado adotou uma política voluntarista (Prost, 1985). Essa demonstração se junta às críticas formuladas por Michel Crozier sobre o fenômeno burocrático, com base em um ponto de vista epistemológico bem diferente (Crozier, 1964), assim como outra leitura da crítica feita por Bourdieu e Passeron recolocando em questão a definição segundo a qual a igualdade tem por base a igualdade de oferta. Esse conjunto de convergências resulta na decisão de desconcentrar-se e de descentralizar-se parcialmente o sistema educativo, com o intuito de simplificar a gestão e, ao mesmo tempo, dar a palavra aos cidadãos, aproximando o ensino das reais condições de vida dos alunos (Derouet, 1996). Esta orientação é central na Lei de Diretrizes e Bases (LDB) de 1989, levada a efeito por Lionel Jospin, que propõe reorganizar o sistema educativo por meio de uma du- pla contratualização: contratualização das relações entre as unidades educacionais e o Estado; contratualização entre as famílias e as unidades. Essa proposta constitui, sem dúvida, a melhor expressão da realidade atual, mas seus diferentes objetivos atrapalham-se mutuamente. Será que é possível, por exemplo, dar a palavra às famílias e desenvolver, ao mesmo tempo, uma ação em favor dos alunos de origem popular? A demanda das famílias é a mesma da das classes médias: querem que seus filhos recebam o melhor ensino possível para poderem destacar-se dos demais. Nessas condições, será que a descentralização constitui um meio de aproximação do sistema de ensino com os alunos, para que eles assumam suas necessidades específicas, ou um recuo do Estado que dá livre curso ao jogo do mercado? Questão insolúvel: as avaliações disponíveis fornecem argumentos para ambas as teses, e é certamente cedo demais para colocar-se um ponto final na discussão e dar-lhe um sentido definitivo.

Esta incerteza acarreta um determinado número de reviravoltas, e é interessante notar, em particular, a evolução de Pierre Bourdieu. Parte das decisões de descentralização inspirava-se na crítica da indiferença diante das diferenças apresentada por Bourdieu e Passeron. No relatório do Collège de France, Pierre Bourdieu até tomava partido em favor de uma concorrência controlada entre as unidades da rede educacional, já que tal concorrência lhe parecia capaz de ser, ao mesmo tempo, fator de eficácia e de igualdade (Propositions pour l'enseignement de l'avenir, 1985). Hoje em dia, o coletivo animado por ele, o "Raison d'agir", denuncia com muita força a autonomia das unidades (Bourdieu \& Charles, 2000), vendo nela, apenas, a demissão do Estado. Nada ilustra melhor as dificuldades da crítica ante a gestores que recuperaram, em parte, as conquistas promovidas por ela e até seguiram as suas recomendações explicitas (Boltanski \& Chiapello, 1999). A refundação da postura crítica exige um novo trabalho. Trata-se de refletir sobre uma nova formulação do problema, que seja sensível aos novos aspectos da questão. É hoje bem visível o aumento das desigualdades entre as unidades (Trancart, 1998), mas não há nenhuma certeza de que isso se 
deva à autonomia das unidades e aos direitos exercidos pelas famílias. A influência das famílias ou das coletividades territoriais sobre as unidades escolares permanece limitada. Muitas dessas desigualdades são fruto dos múltiplos ajustes que são diariamente negociados entre professores e turmas, e que ocorreriam com ou sem autonomia. Ao focalizar as orientações, corre-se o perigo de negligenciar os efeitos do trabalho dos atores: o problema principal talvez não seja o recuo do serviço público diante do mercado, e sim um enfraquecimento do imperativo de justificação entre os atores.

\section{Igualdade, eficácia, "desigualdades justas", a era da gestão e o fim da crítica?}

O ideal de igualdade de oportunidades para alunos de diferentes classes sociais repousava sobre um compromisso entre dois princípios: a exigência cívica de igualdade e a necessidade de operar uma seleção que preparasse a divisão do trabalho. Essa montagem tinha recalcado algumas outras definições de justiça, em particular aquelas que estavam ligadas aos direitos das famílias e das comunidades: tudo isto era transferido para o lado do Ancien Régime (Derouet, 1992). Logo que esse compromisso foi questionado, nos anos de 1960, todos os princípios que ele tinha descartado voltaram à cena. Tal situação, que não se refere apenas à educação, foi teorizada pelos trabalhos de Rawls (1971), e em seguida pelos de Walzer (1983). Esses trabalhos chamam a atenção para a variedade de referências que animam a sociedade e se propõem a definir a democracia como um modo de governo que respeita essa pluralidade. Se reduções dos direitos são necessárias para permitir a decisão, estas devem ser negociadas dentro de uma circulação de saberes e de poderes que dê chances iguais a todos os princípios. E os compromissos que são concluídos devem sempre ser reversíveis. Essa concepção, que é uma forte característica da filosofia política anglosaxã, levou tempo para penetrar no corpo político francês, porque ela não se inscrevia em suas tradições. No entanto, isto está feito. A criação de Zonas de Edu- cação Prioritária $(\mathrm{ZEP})^{6}$ aclimatou a idéia de "desigualdades justas". Do mesmo modo, no âmbito da avaliação, os europeus criticaram muito os estudos americanos por terem reduzido a totalidade do funcionamento da escola a uma única dimensão: a da eficácia. Para contrabalançar a influência desse paradigma foi preciso identificar outras dimensões e formalizar sua definição em um sistema de indicadores: a igualdade, a capacidade de criar uma consciência comum e uma solidariedade coletiva, a capacidade de satisfazer os consumidores inseridos num mercado etc. Outras tantas definições de justiça que guiam efetivamente a ação dos políticos e dos atores. A contribuição desses trabalhos foi retomada, há alguns anos, por uma proliferação de publicações que hesitam entre vários gêneros. Um esclarecimento parece necessário: os trabalhos de Rawls e os de Walzer situam-se claramente do lado da filosofia política. Eles foram retomados pelos sociólogos, que se apóiam neles para levar adiante uma investigação sobre as competências políticas dos atores (Boltanski \& Thévenot, 1991; Dubet 1992). Uma certa confusão instala-se nas publicações mais recentes, que misturam, em dosagens diversas, verdadeiras preocupações científicas e prescrições destinadas ao uso dos que decidem (Van Parijs, 1991; Rosanvallon, 1995; De Munck \& Verhoeven, 1997; Meuret, 1999; Crahay, 2000). Tal confusão corresponde a um mercado: os atores e os políticos experimentam grandes dificuldades em orientar-se entre a multiplicidade de referências possíveis. E muitos consideram o objetivo da igualdade de oportunidades uma casa de marimbondos da qual é preciso se desvencilhar, sem deixar de ser politicamente correto. Uma ciência que não servisse a esclarecer a ação certamente

${ }^{6}$ No início dos anos de 1980, o governo socialista recémeleito instituiu uma política de discriminação positiva no sistema educacional, definindo Zonas Geográficas Prioritárias (ZEPs), localizadas em bairros "problemáticos" (geralmente periferias), nas quais as escolas e os próprios bairros poderiam se beneficiar de uma série de recursos adicionais para compensar suas situações de desvantagem relativa (N.T.). 
não mereceria um minuto de esforço. Mas hoje é grande o perigo de que as ciências sociais sirvam como caução para montagens oportunistas. Uma parte da classe política está à procura de um novo compromisso entre o Estado Providência e o mercado que propõe uma fundamentação teórica a uma nova definição de social-democracia. Os candidatos orientamse, então, para uma posição de intelectual orgânico do novo período. A decisão de engajar-se neste trabalho é direito de todos, contanto que o limite entre a ciência e a política esteja claramente fixado. Em educação, essa evolução se traduz por uma proposição: substituir o ideal de justiça pelo de igualdade. É certo que a igualdade de oportunidades constitui apenas uma das formas de justiça e que a escola não pode ser avaliada somente pela sua influência sobre a mobilidade social. É certo também que a instauração das ZEP mostrou o interesse - mas também os limites - do projeto de "desigualdades justas", e que os novos modos de regulação social devem levar em conta a pluralidade de lógicas dos atores. Deve-se, então, seguir um movimento que corre o risco de levar a um relativismo tão confortável quanto conservador?

Diante de tal derivação, é importante reafirmar a exigência do projeto sociológico: dar um passo em direção à exterioridade para desvencilhar-se do jogo social e da influência daqueles que o dominam.

\section{Luta pela igualdade ou luta contra a exclusão}

Outro deslocamento acompanha o movimento da crise: a problemática da repartição dos benefícios estava marcada pelo contexto dos anos de 1960. É normal que ela se desloque e leve em conta a situação nova criada pelo desemprego e o aumento da exclusão. Deve-se, então, aceitar que um novo objetivo (a luta contra a exclusão) substitua a antiga luta pela igualdade?

Em princípio, as duas não são incompatíveis. No entanto, parece difícil, na prática, mantê-las ao mesmo tempo. $\mathrm{O}$ olhar dos professores não consegue se fixar sobre estes dois horizontes simultaneamente. Nas ZEP, muitos são confrontados com um dilema: situar- se numa perspectiva de igualdade de oportunidades é, no colégio, ${ }^{7}$ organizar o ensino de tal forma que pelo menos uma parte dos alunos possa pretender ter acesso a uma seção nobre do liceu. Tal organização implica um nível de exigência que corre o risco de excluir, de imediato, os mais fracos. Ir buscar os mais fracos onde eles estão significa assumir uma certa flexibilidade em relação aos programas, o que impedirá, mais adiante, os melhores de terem acesso às seções nobres. Seria muito injusto atribuir essa dificuldade aos professores e a sua falta de imaginação pedagógica. Ela sinaliza um problema teórico que não foi suficientemente analisado. A luta pela igualdade e a luta contra a exclusão remetem a modelos de sociedades diferentes. O objetivo de igualdade corresponde à visão dos anos de 1960. A sociedade era concebida como um vasto conjunto no qual grupos - as categorias socioprofissionais do Instituto Nacional de Estatística e de Estudos Econômicos (INSEE), por exemplo - entretinham trocas permanentes. Suas relações podiam evoluir - concorrência, cooperação, aliança, conflito aberto ou paz armada... -, mas estes grupos estavam

${ }^{7}$ N.T.: O sistema educativo francês organiza-se, com relação ao brasileiro, segundo as seguintes correspondências:

Escola Primária

- Curso de Alfabetização (CA) à Curso Preparatório (CP)

- $1^{\mathrm{a}}$ série do Ensino Fundamental à Curso Elementar, $1^{\mathrm{o}}$ ano (CE1)

- $2^{\mathrm{a}}$ série do Ensino Fundamental à Curso Elementar, $2^{\circ}$ ano (CE2)

- $3^{\mathrm{a}}$ série do Ensino Fundamental à Curso Médio, $1^{\mathrm{o}}$ ano (CM1)

- $4^{\mathrm{a}}$ série do Ensino Fundamental à Curso Médio, $2^{\circ}$ ano (CM2)

Colégio

- $5^{\mathrm{a}}$ série do Ensino Fundamental à $6^{\mathrm{a}}$ série (sixième)

- $6^{\mathrm{a}}$ série do Ensino Fundamental à $5^{\mathrm{a}}$ série (cinquième)

- $7^{\mathrm{a}}$ série do Ensino Fundamental à $4^{\mathrm{a}}$ série (quatrième)

- $8^{\mathrm{a}}$ série do Ensino Fundamental à $3^{\mathrm{a}}$ série (troisième)

Liceu

- $1^{\mathrm{o}}$ ano do segundo grau à $2^{\mathrm{a}}$ série (seconde)

- $2^{\circ}$ ano do segundo grau à $1^{a}$ série (première) 
fortemente ligados pelo que estava em jogo na repartição dos benefícios do crescimento. Nesse modelo, o papel do Estado era definir as regras do jogo, proteger os mais fracos das conseqüências dos acordos concluídos entre os poderosos, mas também relançar permanentemente a dinâmica que funda a unidade da sociedade. A escola constituía, certamente, um elemento privilegiado dessa função, na medida em que pretendia redistribuir as posições de uma geração a outra. A luta contra a exclusão refere-se a um outro modelo. A sociedade pode ser descrita como uma curva em forma de sino, cujo centro é constituído por uma enorme classe média, tão grande que se poderia duvidar que ela fosse, realmente, uma classe. Tratase mais de um agregado de indivíduos que partilham um certo número de critérios de definição da normalidade social, mas entre os quais existem diferenças e desigualdades consideráveis. Nas duas extremidades desse sino, duas minorias: uma minoria muito rica, cuja posição e riqueza são definidas nas redes internacionais sobre as quais os Estados têm pouco poder, e uma minoria de excluídos. O papel do Estado é, certamente, o de reintegrar os excluídos no centro do sino, mesmo que seja ao preço de operações que evocam, às vezes, as antigas oficinas de caridade (Rosanvallon, 1995). A oposição fundamental é entre aqueles que estão "fora" e os que estão "dentro". A questão da igualdade entre aqueles que estão "dentro" torna-se então secundária. Vê-se o que está em jogo nesse deslocamento: se uma parte da esquerda política perde sua alma nos compromissos com o mercado, outra parte fica em perigo, limitando sua perspectiva a uma luta contra a exclusão. Na prática, existem escolhas evidentes que são guiadas pela urgência e não se trata de pôr em dúvida o devotamento dos professores que militam nas ZEP. A retomada da questão das desigualdades na educação conduz, no entanto, a uma vigilância tanto política quanto científica. É verdade que a sociedade se fragmentou, que a dinâmica de trocas entre os grupos foi desacelerada e que vários deles ficaram marginalizados. O raciocínio sociológico deve, por isso, renunciar a estabelecer uma relação entre a felicidade dos ricos e a infelicidade dos po- bres? Vê-se facilmente os interesses a que essa concepção poderia servir. Sem ir até às formas extremas que põem em causa a idéia de sociedade, o inconveniente de uma focalização excessiva no problema da exclusão é perder-se de vista a necessidade da referência à globalidade. A exclusão de alguns e as desigualdades que outros sofrem não se remetem a uma mesma causa? É certo que não é fácil pensar nessa causa. O velho conceito de exploração precisa ser renovado, mas é, sobretudo, necessário estabelecer uma ligação entre os resultados de pesquisas cada vez mais etnográficas e tais interpretações "estruturais".

\section{D esigualdades entre os sexos, saberes e relação com o saber: a fecundidade dos questionamentos sobre o sentido da escola}

As análises das desigualdades, realizadas tanto por Bourdieu e Passeron como por Boudon, negligenciavam as diferenças sensíveis - e, por vezes, paradoxais - que existem entre os sexos. Da mesma forma, para a Teoria da Reprodução, a natureza dos saberes escolares situa-se no coração da explicação do fracasso escolar das crianças de origem popular. Mas essa hipótese não é verificada por nenhum estudo empírico. Essas linhas de pesquisa foram muito trabalhadas desde o início dos anos de 1980, e o problema atual é saber se os trabalhos que abordam essas questões se contentam em matizar o modelo antigo, ou se anunciam uma recomposição do campo que prepararia a emergência de um novo paradigma.

A evolução dos interesses científicos é muito ligada ao movimento social. São conhecidas as relações mantidas, na América do Norte, entre os estudos sobre gêneros e o movimento feminista. Essa relação é muito menos sensível na França, mas o interesse suscitado pelo sucesso escolar das meninas corresponde, ainda assim, a uma vontade de questionar os arquétipos que direcionam a orientação dada aos alunos e afastam, por exemplo, as meninas das carreiras técnicas ou científicas (Duru-Bellat, 1990). Temos aqui um movimento que, no decorrer da sua empreitada, acaba por esbarrar na questão do sentido quan- 
do se trata de explicar as diferenças, em termos de sucesso escolar, entre meninas e meninos de uma mesma categoria social. Se deixarmos de lado as explicações que remetem a outros arquétipos (a docilidade das meninas), a explicação mais provável remete ao sentido que as pessoas investem em suas ações. Tal explicação está tornando-se um lugar-comum quando se trata do sucesso escolar das meninas oriundas da imigração. Quanto à questão do saber, tratavase, provavelmente, do ponto cego do projeto de democratização dos anos de 1960. Desde suas origens, o projeto de escola unitária foi alvo de críticos que temiam que a abertura dos liceus tivesse por conseqüência um desaparecimento da cultura clássica. Apesar de combaterem esse argumento, os partidários da democratização não deixavam de lhe ser sensíveis. Na França, a questão da adequação dos programas e da pedagogia ao novo alunado só foi colocada muito tarde e, muitas vezes, de uma forma que justificasse as suspeitas das quais era alvo. O recalcado voltou à tona com toda força e sob várias roupagens quando o projeto de colégio único foi implementado no plano institucional. Havia, é claro, uma nostalgia pura e simples dos bons (velhos) estudos. Mas surgiu, também, uma espécie de discurso de barganha que sacrificava o projeto de democratização do ensino: "A escola não traz igualdade e mobilidade social. É uma pena, mas isto seria menos grave se tivéssemos a certeza de que as crianças aprendem nela alguma coisa”. Esse discurso pode constituir, também, um incentivo para o enriquecimento da noção de democracia, na medida em que, por exemplo, leva a medir a realidade dos progressos da igualdade de acesso ao saber (Thélot, 1993). Tal preocupação deu origem, no final dos anos de 1980, a uma importante reorientação na ação da Direção de Avaliação e Prospectiva do Ministério da Educação Nacional. Foram implementados importantes mecanismos de avaliação nos pontos nodais do sistema educativo: CM2, Sixième, Seconde ${ }^{8}$ Esta preocupação norteia, também, novas orientações cientí-

${ }^{8}$ Ver nota anterior. ficas. Os historiadores já haviam modificado amplamente nossa visão, ao relativizarem a importância dada à escola de Jules Ferry. ${ }^{9}$ Bernard Lahire dá continuidade a esse empreendimento ao estudar, conjuntamente, o sucesso escolar e as práticas domésticas de leitura e escrita (Lahire, 1993). Nesse caso, de novo, a questão do sentido aparece como central: um aluno pode muito bem não ter sucesso em redação escolar e escrever cartas ou um diário íntimo nos quais ele demonstre competências que não aparecem na escola. Essa idéia foi retomada e aprofundada pela equipe de ciências da educação da Universidade de Paris VIII, com o conceito de relação com o saber. Preocupada em demonstrar a dimensão de realidade das ciências da educação, essa equipe cruza múltiplas abordagens: filosofia, lingüística, psicológica... Paradoxalmente, ela vale-se pouco da sociologia, ainda que seu trabalho esteja impregnado de problemáticas sociológicas. Bourdieu e Passeron mostravam bem a relação entre o sucesso escolar e a possibilidade (para os alunos) de descobrir um sentido nos saberes transmitidos pela escola, mas não realizaram nenhum tipo de estudo empírico sobre esta questão. Sua demonstração era puramente teórica e repousava na hipótese de uma harmonia preestabelecida na qual a linguagem e os saberes da escola só têm sentido para as crianças das classes superiores, ao mesmo tempo que afastam as demais. Elisabeth Bautier, Bernard Charlot e JeanYves Rochex retomam essa interrogação, mas diversificam a sua resposta: a capacidade do aluno encontrar, para si, um sentido nos saberes escolares pode ser ligada à origem social, mas ela depende, também, de uma experiência pessoal (Charlot, Bautier \& Rochex, 1993, 1998; Rochex, 1995).

Essa parece ser uma das mais promissoras direções para a recomposição do campo científico, no tocante às desigualdades educacionais. Seu único

${ }^{9}$ No final dos anos de 1870, Jules Ferry foi o ministro da educação que implementou a efetiva universalização da escola "pública, gratuita, laica e obrigatória", dos 7 aos 13 anos, em todo o território francês (N.T.). 
risco é de fechar-se numa abordagem centrada na pessoa do aluno e de cortar esse aspecto da dialética que se desenvolve continuamente entre a definição dos saberes escolares e as competências interpretativas dos alunos. Ao agir dessa forma, ela inverte o procedimento de alguns sociólogos que, ao constatarem o caráter formal dos exercícios escolares, deduziam que as crianças de origem popular eram incapazes de penetrar sua lógica. A abordagem da equipe da Universidade de Paris VIII mostra de forma clara que não existe "código restrito", estabilizado de uma vez por todas (Bernstein, 1975), e que as crianças de origem popular podem perfeitamente ter acesso às formas elaboradas do pensamento, contanto que estas tenham sentido diante de sua experiência. Mas ela negligencia outra vertente: será que todas as formas de elaboração dos saberes escolares oferecem os mesmos recursos para que as crianças possam construir, baseadas nelas, um sentido para si? Isso nos remete a uma sociologia do currículo que trabalhe na construção dos programas escolares. A verdadeira crítica não se refere à questão do enciclopedismo, mas à da coerência dos programas. Se os saberes podem ser organizados com base em um pequeno número de princípios simples, sua quantidade pode ser dominada pelo aluno. Em compensação, quando se trata de saberes incoerentes e sem relação com o que está em jogo na experiência dos alunos, ainda que o ministro aligeire ao infinito os programas, sua insignificância só terá por resultado aumentar as dificuldades enfrentadas pelos professores. A isso se acrescenta o problema da assimilação da crítica por estes professores (Derouet, 2000). Se o objetivo é progredir, tanto no plano político quanto no científico, é fundamental que haja uma articulação entre duas formas de encaminhamento: aquela que estuda o modo de construção dos saberes escolares e joga uma luz sobre as armadilhas que os programas podem comportar e aquela que toma como ponto de partida os alunos, estudando a maneira pela qual os saberes podem ganhar sentido diante de sua experiência. Essas duas abordagens deveriam, sem dúvida, ser complementadas por uma terceira que tivesse como objeto a interpretação local dos programas e os deslocamentos que estes podem acarretar.

\section{Conclusão: \\ Segunda explosão escolar, novas abordagens das desigualdades e reinício da crítica}

Desde os anos de 1960, numerosos trabalhos tentam fazer um balanço das políticas de democratização (Duru-Bellat \& Kieffer, 1999; Merle, 2000). Um dos problemas é que os indicadores se movem junto com o objeto observado. Durante muito tempo, as estatísticas de acesso à sixième, e depois ao liceu ou ao ensino superior, eram considerados indicadores de democratização do ensino. A partir de meados dos anos de 1980, os sociólogos e os políticos começaram a estabelecer uma distinção entre massificação e democratização, sem contudo resolver o problema das relações entre essas duas noções. Alguns só vêem na massificação um quadro de vida ou uma translação para o alto das desigualdades (Oeuvrard, 1979; Coëffic, 1996; Duru-Bellat \& Merle, 1997). Outros julgam que a massificação favorece, globalmente, a democratização (Langoüet, 1994). Encontramos aqui um dos componentes fundamentais da pós-modernidade. Tornou-se impossível fazer sociologia das desigualdades sem fazer, ao mesmo tempo, sua epistemologia, isto é, sem relacionar os dados aos sistemas no seio dos quais eles foram construídos (Briand, Chapoulie \& Peretz, 1979; Combessie, 1984; Ungerer, 1987; Duru-Bellat \& Mingat, 1992; Vallet, 1998, 1999). Tal é, sem dúvida, o preço a pagar para que possamos objetivar, ao mesmo tempo, uma compreensão mais exata dos novos aspectos do problema e uma retomada da crítica.

Com certeza, pode ser perigoso substituir o ideal de justiça pelo ideal de igualdade. No entanto, todo questionamento sobre as desigualdades deve integrar os aportes dos trabalhos contemporâneos no que se refere à pluralidade das definições de justiça. A segunda explosão escolar dos anos de 1980 visa à igualdade, tanto quanto a dos anos de 1960, mas ela de- 
senvolve-se num contexto diferente e a definição de igualdade diversificou-se. Já não há mais um consenso em torno de uma definição única de Bem Comum como pôde existir acerca do objetivo de igualdade de oportunidades. A avaliação do papel da escola na sociedade deve levar em conta essa realidade. A ampliação do olhar não corresponde, forçosamente, a uma perda de substância, contanto que essa avaliação permaneça no interior do espaço político. A dificuldade de orientar-se entre as diferentes definições pode, de fato, levar a diversas formas de relativismo. Alguns tomam a forma aberta e quase insolente de estratégias de sobrevivência: "Gosto dos meus princípios, mas entre os meus princípios e a minha pele, prefiro minha pele". Essa atitude extrema é, todavia, marginal e gera desconforto naqueles que a desenvolvem. A derivação mais inquietante é aquela que se desvia da justiça dos princípios para concentrar-se unicamente na justeza dos dispositivos. Muitos especialistas em ciências políticas propugnam por um sistema de governança. A pilotagem nacional seria complementada por lugares de regulação local, nos quais se encontrariam os diversos parceiros interessados pela ação pública (Kooiman, 1993; Dutercq, 1999). No caso da escola, tratar-se-ia tanto dos professores e da administração da educação nacional quanto dos pais de alunos, das coletividades territoriais, das empresas etc. Esse princípio pode ser a melhor ou a pior das coisas. As unidades escolares e os territórios educativos são, sem dúvida, lugares nos quais as pessoas podem reconstituir o laço que deve unir o que está em jogo na sua vida cotidiana às missões gerais do sistema. Mas, para isso, é preciso que o debate aborde os problemas de fundo, isto é, os problemas políticos, e que não se limite apenas à questão da gestão.

Por mais variadas que sejam as definições da justiça, todas atribuem, hoje em dia, uma grande importância ao saber. Esse interesse não é propriedade de alguns filósofos mediáticos, mas constitui preocupação para todos aqueles que constatam a quantidade e a complexidade das competências necessárias para ser um membro normal da sociedade. Por isso, não é ruim que a escola volte às suas fontes: seu papel é promo- ver o incremento do conhecimento, a possibilidade, para as pessoas de desenvolverem suas competências e darem sentido à sua vida pelo saber. Ao mesmo tempo, não é possível desconectar totalmente a formação das pessoas da sua posição social. Os estudos históricos mostram um progresso inconteste dos conhecimentos adquiridos pelos alunos (Baudelot \& Establet, 1988; Dessus, 1996), e o rendimento do trabalho beneficia esse crescimento. Isso coloca, em primeiro lugar, problemas para sua organização, para que o progresso do conhecimento corresponda a uma difusão do pensamento crítico na sociedade. Jovens formados para ter um espírito crítico não podem aceitar obedecer sem compreender (Eckert, 1992). Mas isso tem sobretudo por efeito colocar, de uma forma nova, o problema da mobilidade social: até quando a repartição das posições pode permanecer surda à nova repartição das competências? (Euriat \& Thélot, 1995; Goux \& Maurin, 1995)

JEAN-LOUIS DEROUET é professor de sociologia no Institut National de Recherche Pédagogique, na França, onde dirige o Département "Politiques, Pratiques et Acteurs de l’Éducation". Trabalha com sociologia política da educação, especialmente com questões relacionadas ao direito à educação. E-mail: derouet@inrp.fr

\section{Referências bibliográficas}

BACZKO, B., (1982). Une éducation pour la démocratie: textes et projets de l'époque révolutionnaire. Paris: Gamier.

BAUDELOT, C., ESTABLET, R., (1988). Le niveau intellectuel des jeunes conscrits ne cesse de s'élever. Économie et Statistique, $\mathrm{n}^{\mathrm{o}} 207$.

BAUTIER, E., ROCHEX, J.-Y., (dir.) (1998). L'expérience scolaire des "nouveaux lycéens": démocratisation ou massification? Paris: A. Colin.

BERNSTEIN, B., (1975). Langage et classes sociales: codes socioIinguistiques et contrôle. Paris: Minuit.

BOLTANSKI, L., (1996). Une sociologie sans société. La Lettre de l'Association pour la Recherche à l'EHESS, no 14. 
BOLTANSKI, L., CHIAPELLO, E., (1999). Le nouvel esprit du capitalisme. Paris: Gallimard.

BOLTANSKI, L., THÉVENOT, L., (1991). De la justification. Les économies de la grandeur. Paris: Gallimard.

BOUDON, R., (1977). Effets pervers et ordre social. Paris: PUF. , (1973). L'inégalité des chances. La mobilité sociale dans les sociétés industrielles. Paris: A. Colin.

BOURDIEU, P., CHARLES, Ch., (2000). Un ministre ne fait pas le printemps. Le Monde, 8 avril 2000.

BOURDIEU, P., PASSERON, J.-C., (1970). La reproduction. Éléments pour une théorie du système d'enseignement. Paris: Minuit. , (1964). Les héritiers. Les étudiants et la culture. Paris: Minuit.

BRIAND, J.-P., CHAPOULIE, J.-M., PERETZ, H., (1979). Les statistiques scolaires comme représentation et comme activité. Revue Française de Sociologie, v. XX.

CHARLOT, B., BAUTIER, E., ROCHEX, J.-Y., (1993). École et savoir dans les banlieues... et ailleurs. Paris: A. Colin.

CRAHAY, M., (2000). L'école peut-elle être juste et efficace? De l'égalité des chances à l'égalité des acquis. Bruxelles: De Boeck.

COËFFIC, N., (1996). Amélioration des carrières scolaires au collège, mais maintient d'orientations différentiées en fin de troisième. In: La société française; données sociales. Paris: INSEE.

COMBESSIE, J. C., (1984). L'évolution comparée des innégalités: problèmes statistiques. Revue Française de Sociologie, v. XXV-2.

CROZIER, M., (1991). État modeste, État moderne: stratégies pour un autre changement. Paris: Le Seuil. ,(1964). Le phénomene bureaucratique. Paris: Le Seuil.

DARRAS, (1966). Le partage des bénéfices: expansion et inégalités en France. Paris: Minuit.

DE MUNCK, J., VERHOEVEN, M., (dirs.) (1997). Les mutations $d u$ rapport à la norme: un changement dans la modernité? Bruxelles: De Boeck.

DEROUET, J. L., (1996). De nouveaux espaces de formulation de I'intérêt général: le cas des établissements scolaires. In:
GREMION, C., FRAISSE, R. (eds.). Le service public en recherche.Quelle modernisation? Paris: La Documentation Française.

, (dir.) (1999). L'école dans plusieurs mondes. Paris/ Bruxelles: De Boeck/INRP.

(1992). École et justice. De l'égalité des chances aux compromis locaux? Paris: A. M. Métailié.

, (2000). L’identité enseignante dans une société critique. In: ABOU, A., GILETTI, M. J. (coords.), Enseignants d'Europe et d'Amérique. Questions d'identité et de formation. Paris: INRP.

DESROSIÈRES, A., (1993). La politique des grands nombres. Histoire de la raison statistique. Paris: La Découverte.

DESSUS, N. et al., (1996). Les connaissances des élèves en fin de troisième générale. Évolution 1984-1990-1995. Note d'Information, $\mathrm{n}^{\mathrm{o}} 36$.

DUBET, F., (1992). Massification et justices scolaires: à propos d'un paradoxe. In: AFFICHARD, J., FOUCAULT (de), J. B. Justice sociale et inégalités. Paris: Esprit. , (1994). Sociologie de l'expérience. Paris: Le Seuil.

DURU-BELLAT, M., (1990). L'école des filles: quelle formation pour quels rôles sociaux? Paris: L'Harmattan.

DURU-BELLAT, M., KIEFFER, A., (1999). Évaluer la démocratisation de l'enseignement: la situation française à l'épreuve des comparaisons internationales. Revue Française de Pédagogie, $\mathrm{n}^{\mathrm{o}} 127$.

DURU-BELLAT, M., MERLE, P., (1997). La démocratisation impossible? Usages sociaux de l'école et inégalités sociales des cursus scolaires. Savoir Éducation-Formation, $\mathrm{n}^{\mathrm{o}}$ 3-4.

DURU-BELLAT, M., MINGAT, A., (1997). La constitution de classes de niveau dans les collèges: les effets pervers d'une pratique à visée égalisatrice. Revue Française de Sociologie, v. XXXVIII-4.

, (1992). Un regard analytique sur la démocratisation de l'enseignement: valeur heuristique et problèmes méthodologiques des comparaisons dans le temps. Sociétés Contemporaines, $\mathrm{n}^{\mathrm{o}}$ 11-12.

DUTERCQ, Y., (1999). Vertus et limites d'un gouvernement local éducatif. Administration et Éducation, $\mathrm{n}^{\circ} 2$. 
ECKERT, H., (1992). L'émergence d'un ouvrier bachelier. Les "bac pro" entre déclassement et recomposition de la catégorie des ouvriers qualifiés. Revue Française de Sociologie, v. XL-2.

EURIAT, M., THÉLOT, C., (1995). Le recrutement social de l'élite scolaire en France. Évolution des inégalités de 1950 à 1990. Revue Française de Sociologie, v. XXXVI-3.

GIRARD, A., BASTIDE, H., (1963). La stratification sociale et la démocratisation. Population, $\mathrm{n}^{\circ} 2$.

GIRARD, A., BASTIDE, H., PORCHER, G., (1963). Enquête nationale sur l'entrée en sixieme et la démocratisation. Population, $\mathrm{n}^{\circ} 1$.

GOUX, D., MAURIN, E., (1995). Origine sociale et destinée scolaire. L'inégalité des chances devant l'enseignement à travers les enquêtes Formation-Qualification Professionnelles 1970, 1977, 1985 et 1993. Revue Française de Sociologie, v. XXXVI-1.

KOOIMAN, J. (ed.) (1993). Modern governance: new government-society interactions. London: Sage.

LAHIRE, B., (1993). Culture écrite et inégalités scolaires: sociologie de l' échec scolaire à l' école primaire. Lyon: Presses Universitaires de Lyon.

LANGOÜET, G., (1994). La démocratisation de l'enseignement aujourd'hui. Paris: ESF.

MERLE, P., (2000). Le concept de démocrarisation de l'institution scolaire: une typologie et sa mise à l'épreuve. Population, $\mathrm{n}^{\mathrm{o}} 55$ (1)

MERLE, P., MEAR, P., (1992). 1986-1990: Démocratisation et/ ou hiérarchisation sociale croissante des publics lycéens. Sociétés Contemporaines, $\mathrm{n}^{\mathrm{o}} 11$.

MEURET, D. (dir.) (1999). La justice du système éducatif. Bruxelles: De Boeck.

NORVEZ, A., (1977). Le corps enseignant et l'évolution démographique. Effectifs des enseignants du second degré et besoins futurs. Paris: INED (Cahiers Travaux et Documents), nº 82.

OEUVRARD, F., (1979). Démocratisation ou élimination différée? Actes de la Recherche en Sciences Sociales, $\mathrm{n}^{\circ} 30$.

PROPOSITIONS POUR L'ENSEIGNEMENT DE L'AVENIR, (1985). Élaborées à la demande de Monsieur le Président de la
République par les professeurs du Collège de France. Paris: Collège de France.

PROST, A., (1993). Éducation, société et politiques. Une histoire de l'enseignement en France de 1945 à nos jours. Paris: Le Seuil. (1981). L'école et la famille dans une société en mutation. In: PARIAS, L. H. (dir.) Histoire générale de l' enseignement et de l' éducation. Paris: Nouvelle Librairie de France, t. IV. , (1985). Les lycées et leurs études au seuil du XXIe siècle: rapport du groupe de travail national sur les seconds cycles. Paris: Ministère de l'Éducation Nationale.

RAWLS, J., (1971). A theory of justice. Harvard: Harvard University Press.

RAYOU, P., (1998). La cité des lycéens. Paris: L’Harmattan.

ROCHEX, J. Y., (1995). Le sens de l'expérience scolaire. Paris: PUF.

ROSANVALLON, P., (1995). La nouvelle question sociale. Repenser 1' État-providence. Paris: Le Seuil.

THÉLOT, C., (1993). L'évaluation du système éducatif: coûts, fonctionnement, résultats. Paris: Nathan.

TRANCART, D., (1998). L'évolution des disparités entre collèges publics. Revue Française de Pédagogie, n 124.

UNGERER, C., (1987). La double vision de la sélection scolaire. Retour sur une enquête de l'INED. Revue Française de Sociologie, v. XXVIII-2.

VALLET, L. A., (1998). L'évolution de l'inégalité des chances devant l'enseignement. Un point de vue de modélisation statistique. Revue Française de Sociologie, v. XXIX-3.

(1999). Quarante années de mobilité sociale en France. L'évolution de la fluidité sociale à la lumière des modèles récents. Revue Française de Sociologie, v. XL-1.

VAN HAECHT, A., (1985). L'enseignement rénové de l'origine à l'éclipse. Bruxelles: Éditions de 1’Université de Bruxelles.

VAN PARIJS, P., (1991). Qu'est-ce qu'une société juste? Paris: Le Seuil.

WALZER, M., (1983). Spheres of justice. A defence of pluralism and equality. Oxford: Basil Blackwell. 


\section{Resumos/Abstracts}

Jean-Louis Derouet

A sociologia das desigualdades em educação posta à prova pela segunda explosão escolar: deslocamento dos questionamentos e reinício da crítica

Analisa exemplarmente o caso francês, considerando inicialmente duas cronologias: uma longa, que se enraíza nos planos de educação da segunda metade do século XVIII, ligando a igualdade educativa à construção da unidade nacional e ao exercício da cidadania; outra curta, mais recente, que corresponde ao projeto da escola única e na qual a questão da mobilidade social é central. O tema das desigualdades educacionais aparece na França ao final dos anos de 1950. No entanto, a segunda explosão escolar, que ocorre a partir dos anos de 1980, e a ineficácia relativa das alternativas experimentadas no sistema educativo, entre elas a descentralização, exigem nova formulação do problema, em particular levando em conta a nova situação criada pelo desemprego e pelo aumento da exclusão.

Palavras-chave: sociologia da educação, desigualdades em educação.

The sociology of inequalities in education put to the test by the second school explosion: changing the questions and restarting the criticism The article analyses the French case considering initially two different chronologies: a long term one which is rooted in the educational plans of the second half of the $18^{\text {th }}$ century, linking educational equality with the construction of national unity and to the exercise of citizenship and, a more recent short-term chronology that corresponds to the project of the unitary school in which the question of social mobility is central. The theme of educational inequalities appears in France at the end of the 1950's. However the second school explosion which starts in the 1980's and the relative inefficiency of the alternatives tested in the educational system, amongst which decentralisation, demand a new formulation of the problem, taking into account the new situation created by unemployment and the increase in exclusion.

Key-words: education sociology, inequalities in education.

Maria Isabel Edelweiss Bujes

A invenção do eu infantil: dispositivos pedagógicos em ação

Este trabalho se insere no terreno das discussões que pretendem examinar as relações entre infância e poder. Tomando como seu foco principal o Referencial Curricular Nacional para a Educação Infantil (RCN), ele pretende apontar para as formas como operam os dispositivos de governamento da infância, a partir da racionalidade gover- namental moderna. A investigação, de inspiração foucaultiana, propõe-se a destacar também como os aparatos de poder/saber que se relacionam com a infância, com seus sistemas de enunciados verdadeiros, são produzidos no interior das relações pedagógicas. Neste artigo, realiza-se uma analítica de governamento da infância, a partir das proposições presentes no documento examinado. Destacam-se, neste exame, os modos de operar daquilo que Michel Foucault denominou de tecnologias $d a$ experiência de si ou tecnologias do eu. Associado às tecnologias políticas e às racionalidades de governamento, ressalta-se o RCN como dispositivo de produção das subjetividades infantis, uma vez que ele propõe a organização, a disseminação e o controle do saber que circula nas instituições de educação infantil.

Palavras-chave: educação infantil, tecnologias do eu, subjetividade infantil, dispositivos de poder.

Inventing the child's self: pedagogical dispositifs in action This work was conceived within the discussions that propose to analyse connections between power and early childhood. Choosing as its main focus the National Curriculum for Early Childhood Education - Referencial Curricular Nacional para a Educação Infantil (RCN) -, this study intends to problematise the ways governmental 